\title{
Emolehmien ja karitsoiden yhteislaiduntaminen ei lisännyt loisongelmaa laidunpaineen kasvaessa
}

\author{
Riitta Sormunen-Cristian ${ }^{1}$, Merja Manninen ${ }^{1,2}$, Lauri Jauhiainen ${ }^{1}$ ja Antti Oksanen ${ }^{3}$ \\ ${ }^{1}$ MTT, Maa- ja elintarviketalouden tutkimuskeskus, 31600 Jokioinen, etunimi.sukunimi@mtt.fi; \\ ${ }^{2}$ Nykyinen osoite: Hutkankatu 8, 30420 Forssa, mmanninen@luukku.com; \\ ${ }^{3}$ Elintarviketurvallisuusvirasto Evira, Oulun tutkimusyksikkö, PL 517, 90101 Oulu, etuni- \\ mi.sukunimi@evira.fi
}

\section{Tiivistelmä}

Märehtijöissä on lähes aina loisia, jotka saattavat aiheuttaa vakaviakin terveysongelmia. Lieväkin tartunta hidastaa eläimen kasvua. Ennaltaehkäisyssä on tärkeää, että loistartunnalle herkät nuoret karitsat ja vasikat pääsevät laiduntamaan puhtaita, edellisenä kesänä käyttämättömiä alueita. Mikäli tämä ei ole mahdollista, loisia pyritään torjumaan tietyn häätöohjelman mukaisesti. Loislääkitys lisää kustannuksia. Lääkityksen jatkuva käyttö mahdollistaa myös loislääkkeille vastustuskykyisten kantojen syntymisen. Loisongelman torjuntaan on käytetty myös erilaisia laiduntamisstrategioita kuten alennettua eläintiheyttä, lohkosyöttöä ja yhteislaidunnusta. Eri eläinlajien yhteislaidunnus on vähentänyt märehtijöiden loisongelmaa yhden lajin laiduntamiseen verrattuna. Huolimatta lupaavista tuloksista ulkomailla ei yhteislaiduntamisen merkitystä lampaiden ja nautojen loistilanteeseen ole aikaisemmin maassamme tutkittu.

Emolehmien ja karitsoiden yhteislaiduntamista ja yhteislaiduntamisen vaikutusta märehtijöiden sisäloisiin ja painonmuutoksiin tutkittiin Laatulihaa tehokkaalla emolehmätuotannolla -hankkeessa MTT:n emolehmänavetalla Tohmajärvellä 2003 - 2004. Tutkimuksessa oli molempina kesinä 32 hereford-emolehmää ja näiden 32 vasikkaa sekä 90 suomenlammaspässikaritsaa. Kesällä 2003 oli mukana myös 4 sonnia. Naudat olivat neljässä 8 emon, 8 vasikan ja yhden sonnin ryhmässä. Kahdessa nautaryhmässä oli lisäksi 45 karitsaa. Yhtä ryhmää varten laidunta oli 4,2 ha jaettuna kolmeen yhtä suureen syöttökaistaan. Laidun oli kesällä 2003 toisen vuoden nurmea ja siinä oli ensimmäisen laidunnuksen alkaessa 42 \% timoteita, 23 \% nurminataa ja 18 \% puna-apilaa. Yksilölliset sonta- ja papananäytteet otettiin laidunkauden alussa ja lopussa sekä kuukauden välein. Loismääritykset tehtiin Eviran Oulun tutkimusyksikössä. Nautoja ja karitsoita ei loislääkitty ennen koetta eikä kokeen aikana.

Kesän 2003 ensimmäisissä sonta- ja papananäytteissä todettiin yli 80 prosentissa loisten munia tai munia vastaavia kestomuotoja (ookystia). Lähes kaikissa papananäytteissä oli runsaasti kokkidiookystia (Eimeria spp.). Eimeria-ookystia löytyi myös emoilta, vasikoilta ja astutussonneilta. Nämä olivat erittäin todennäköisesti eri lajeja kuin karitsoilla. Kenties kuivan ja kuuman sään ansiosta kokkidimäärät heinä- ja elokuussa 2003 selvästi vähenivät. Emolehmät tuottivat koko laidunkauden ajan ja vasikat ja karitsat keski- ja loppukesästä pieniä määriä Trichostrongylidae-heimon sukkulamatojen munia. Naudalla nämä mahdollisesti olivat enimmäkseen Ostertagia ostertagi -juoksutusmahamadon munia. Karitsoiden tartunta tuli mahdollisesti alkuperätilalta. Trichostrongylidae-munia oli korkeimmillaan vain $200 \mathrm{kpl}$ sontagrammassa eli selvästi alle sen määrän, mitä yleensä tavataan, kun loistartunta vaarantaa eläimen terveyttä. Toisen kesän sateisten sääolojen pelättiin olevan edullisia loisten kasvulle. Suuria muutoksia ei loismäärissä kuitenkaan tapahtunut. Vasikoiden kasvu oli pelkällä nautalaitumella parempi kuin yhteislaitumella, mutta noin 140 gramman päiväkasvueroa pidettiin käytännön kannalta merkityksettömänä. Karitsat kasvoivat laidunkauden aikana tyydyttävästi, keskimäärin noin 160 grammaa päivässä. Yhteislaiduntaminen lisäsi lihan kokonaistuottoa hehtaarilla keskimäärin 120 kiloa. Tuoton lisäys tuli karitsoista.

Karitsoiden mukanaolo nosti laidunpainetta $21 \%$ :lla, mutta sillä ei ollut haitallista vaikutusta emojen, vasikoiden eikä karitsoiden loismääriin. Tämä selittynee osittain sillä, että laidunalue oli aikaisemmin laiduntamatonta nurmea ja että nautojen ja karitsoiden välillä oli vähän loisten ristiintartuntoja.

Asiasanat: Eimeria, kokkidi, emolehmä, laidun, loiset, sukkulamadot, karitsa, nurmi, yhteislaidun 


\section{Johdanto}

Tehokas, mutta eläinten hyvinvointia arvostava tuotanto vaatii jatkuvaa loisseurantaa. Sisäloiset, joita ovat mm. alkueläimiin kuuluvat kokkidit, sekä heisi-, maksa- ja sukkulamadot (esimerkiksi juoksutusmaha- ja keuhkomadot), alentavat syöntiä, aiheuttavat sairauksia ja pahimmassa tapauksessa saattavat aiheuttaa eläimen menehtymisen. Loisten aiheuttamat tuotostappiot niin lammas- kuin nautakarjatiloillakin ovat merkittävät. Viljelijät luottavat usein lääkityksen voimaan eläinten terveyden ja hyvinvoinnin ylläpidossa. Loislääkitys on kustannustehokasta, mutta sen jatkuva käyttö voi johtaa lääkitykselle vastustuskykyisten loiskantojen syntymiseen (Jackson ja Coop 2000). Loisongelmaa on pyritty hillitsemään ja torjumaan myös erilaisilla laiduntamisstrategioilla. Näitä ovat sopivan alhainen eläintiheys, lohkosyöttö eli ns. kiertävä laidunnus ja yhteislaidunnus. Yhteislaidunnus, jossa aluetta laidunnetaan joko yhtä aikaa tai vuorotellen eri eläinlajeilla, on ulkomaissa tutkimuksissa antanut lupaavia tuloksia. Yhteislaiduntaminen on vähentänyt märehtijöiden loisongelmaa yhden eläinlajin laiduntamiseen (monolaiduntaminen) verrattuna (Jordan ym. 1988). Positiivinen vaikutus johtuu siitä, että yhteislaitumella naudat syövät lampaiden loisten saastuttamaa ruohoa ja vähentävät täten lampaiden uudelleen tartuntaa, ja päinvastoin. Suurin osa merkittävistä loisista on lajispesifisiä. Loislääkityksen poisjättäminen vähentää kustannuksia ja muodostaa kuluttajalle mielikuvan ekologisemmasta kotieläintuotannosta. Yhteislaiduntamisen merkitystä lampaiden ja nautojen hyvinvointiin ei aikaisemmin maassamme ole tutkittu. Tässä tutkimuksessa verrattiin emolehmien ja näiden vasikoiden kasvattamista laitumella joko yksinään tai yhdessä karitsoiden kanssa sekä laiduntamisstrategian vaikutusta eläinten loismääriin, terveyteen ja painonkehitykseen.

\section{Aineisto ja menetelmät}

Tutkimus toteutettiin Laatulihaa tehokkaalla emolehmätuotannolla -hankkeessa Maa- ja elintarviketalouden tutkimuskeskuksen (MTT) emolehmänavetalla Tohmajärvellä 2003 - 2004. Kokeen alkaessa laidun oli toisen vuoden timotei (42 \%)-nurminata (23 \%)-puna-apilanurmea (18 \%). Tarkemmat tiedot mm. kokeen perustamisesta ja lannoittamisesta ilmenevät Maataloustieteen Päivien esityksestä vuodelta 2006 (Sormunen-Cristian ym. 2006). Naudat olivat MTT:n omasta karjasta. Karitsat ostettiin toiselta valtion tilalta.

Tutkimuksessa oli kaksi nauta- ja kaksi nauta-karitsaryhmää. Nautaryhmässä oli 8 emoa, 8 vasikkaa ja astutussonni (ryhmä 1) sekä nauta-karitsaryhmässä nautojen lisäksi 45 suomenlammaspässikaritsaa (ryhmä 2). Tutkimuksesta riippumattomista syistä astutussonnit eivät olleet mukana enää kesällä 2004. Jokaista ryhmää varten laidunta oli 4,2 ha. Laidunnus kesti kesäkuun alusta elokuun loppuun 83 päivää. Laidunpaine hehtaarilla, nautayksikkönä (ny=500-kiloinen lehmä) ilmoitettuna, oli ensimmäisen laidunkesän alkaessa 3,2 ny nautaryhmässä ja 3,8 ny nauta-karitsaryhmässä ja seuraavan laidunkesän alkaessa vastaavasti 2,9 ja 3,6 ny. Koska aluetta ei aikaisemmin ollut laidunnettu, eläimiä ei loislääkitty. Eläimet punnittiin laidunkauden alussa ja lopussa sekä 28 päivän välein. Emot kuntoluokitettiin (Lowman ym. 1976) kaksi kertaa kesässä. Punnitusten yhteydessä papana- ja sontanäytteet otettiin suoraan peräsuolesta loismäärityksiä varten. Loismääritykset tehtiin Eviran Oulun tutkimusyksikössä kvantitatiivisella flotaatiomenetelmällä (modifioitu McMaster -menetelmä). Ookystien (oocysts per gram, opg) ja munien (eggs per gram, epg) määrä ilmoitettiin kappaleina sontagrammassa.

Eläinten painonmuutos- ja kuntoluokitusdata analysoitiin lineaarisilla sekamalleilla käyttäen SAS/MIXED-proseduuria. Valituissa malleissa koeyksikköinä pidettiin koeruutua, johon käsittelyt oli kohdistettu. Samassa ruudussa olleiden eläinten tulosten korreloituminen huomioitiin (Morris 1999).

\section{Tulokset ja tulosten tarkastelu}

Päivien keskilämpötilat touko-syyskuussa vastasivat normaalia keskilämpötilaa (kesät 2003 ja 2004: 12,9 ja $12,5^{\circ} \mathrm{C}$, kesät 1971-2000: $\left.12,1^{\circ} \mathrm{C}\right)$. Heinäkuu 2003 oli erityisen lämmin $\left(19,5^{\circ} \mathrm{C}\right)$. Koekesien sademäärä oli 40-80 mm normaalia suurempi. Etenkin elokuu 2003 oli sateinen. Tällöin satoi lähes kaksi kertaa enemmän kuin 30 vuoden aikana elokuussa keskimäärin (160 vs. 83 mm).

Kesän 2003 ensimmäiset näytteet kerättiin kahden viikon kuluttua laidunnuksen alkamisesta 18. päivänä kesäkuuta. Papanat saatiin 80 \%:sta karitsoita ja sontanäytteet 90 \%:sta nautoja. Näissä näytteissä todettiin yli 80 prosentissa loisten munia tai munia vastaavia kestomuotoja (ookystia). Suolistoloisista yleisimmät olivat alkueläimiin kuuluvat Eimeria spp.-kokkidit (Taulukko 1). Näitä oli lähes kaikissa papananäytteissä. Alkueläin lisääntyy lampaan ohutsuolessa tuottaen suuria määriä ookystia, 
jotka eritetään ulosteessa. Ookystien eritys on huipussaan 8-12 päivää laitumelle laskun jälkeen. Maassa ookystat kehittyvät tartuntakykyisiksi, sporuloituvat, jolloin niissä muodostuu ns. sporotsoiitteja, muutamassa päivässä. Kuten Gudmundssonin ym. (1984) tutkimuksessa kokkidiookystia oli papanoissa runsaasti laidunkauden alussa kesäkuussa. Neljä karitsaa, joilla esiintyi myös ripulia, eritti kokkidiookystia yli 50000 opg. Määrää on pidettävä karitsalle suurena. Enimmillään karitsoiden kokkidiookystia oli 432000 opg. Lämmin ja kuiva sää heinäkuussa 2003 ilmeisesti esti liikkumiskyvyttömien ookystien leviämistä ruohoon ja mahdollisesti tappoi niitä myös kuivuuteen, ja niinpä kokkidiookystien määrä karitsoissa oli alimmillaan elokuussa. Eimeria-ookystia löytyi myös emoilta, vasikoilta ja astutussonneilta. Nämä olivat erittäin todennäköisesti eri lajeja kuin karitsoilla. Kullakin eläinlajilla on omat kokkidinsa. Lampaalla merkityksellisiä lajeja tunnetaan kymmenkunta ja naudalla hieman enemmän. Tartuntaa eri eläinlajien välillä ei tapahdu.

Taulukko 1. Eimeria-ookystat (opg) ja Trichostrongylidae-heimon lajien munat (epg) keskimäärin yhdessä sontagrammassa kesinä 2003-2004.

\begin{tabular}{|c|c|c|c|c|c|c|c|c|c|c|c|c|}
\hline & \multicolumn{6}{|c|}{ Eimeria-ookystat } & \multicolumn{6}{|c|}{ Trichostrongylidae } \\
\hline & \multicolumn{3}{|c|}{2003} & \multicolumn{3}{|c|}{2004} & \multicolumn{3}{|c|}{2003} & \multicolumn{3}{|c|}{2004} \\
\hline & Kesä & Heinä & Elo & Kesä & Heinä & Elo & Kesä & Heinä & Elo & Kesä & Heinä & Elo \\
\hline \multicolumn{13}{|l|}{ Naudat yksin } \\
\hline Vasikat & 623 & 56 & 138 & 2005 & 355 & 444 & 0 & 10 & 18 & 0 & 196 & 179 \\
\hline Emot & 50 & 2 & 9 & 46 & 51 & 121 & 21 & 23 & 26 & 41 & 41 & 24 \\
\hline \multicolumn{13}{|l|}{ Yhteislaidun } \\
\hline Vasikat & 313 & 64 & 115 & 2595 & 728 & 336 & 0 & 10 & 6 & 8 & 199 & 188 \\
\hline Emot & 81 & 3 & 11 & 40 & 73 & 11 & 10 & 8 & 8 & 6 & 44 & 26 \\
\hline Karitsat & 21466 & 7880 & 1588 & 8045 & 4645 & 2377 & 0 & 0 & 3 & 0 & 58 & 72 \\
\hline
\end{tabular}

Ensimmäiset näytteet otettiin 18.6.2003 ja 8.6.2004 ja muut näytteet heinä- ja elokuun lopussa.

Sukkula- eli pyörömadot (nematodit) ovat yleisimpiä lampaan loisia. Tässä tutkimuksessa useimmat pyörömadot kuuluivat Strongyloides-sukuun ja Trichostrongylidae-heimon lajeihin. Strongyloidesloisten munia oli erityisen paljon vasikoissa kesäkuussa molempina vuosina. Kahdesta vasikasta löytyi Strongyloides-loisten munia jopa 1700 ja 2700 epg. Emot olivat molempina kesinä lähes puhtaat. Koska alue oli laitumena ensimmäistä kertaa, sukkulamatojen määrä oli yleensä alhainen.

Laidunkauden alussa 2003 löytyi pieniä määriä Trichostrongylidaes-heimon matojen, mahdollisesti Ostertagia ostertagi -juoksutusmahamatojen, munia emoista (maks. 180 epg) ja sonnista (maks. 200 epg). Vasikat (maks. 120 epg) ja karitsat (maks. 40 epg) erittivät tämän heimon munia laidunkauden lopussa. Toisena kesänä kaikki eläinryhmät erittivät Trichostrongylidae-munia enemmän kuin ensimmäisenä kesänä. Määrät eivät kuitenkaan olleet haitallisen suuria. Mikäli munia on noin 3000 kpl sontagrammassa, eläin voi sairastua. Vaikka loiset ovatkin eläinlajille tyypillisiä, niin tutkimuksessamme ei voida täysin poissulkea mahdollisuutta, etteivätkö karitsat olisi saaneet $O$. ostertagi tartuntaa naudoista. Todennäköisempää kuitenkin on, että karitsoiden erittämät munat olivat lampaan juoksutusmahamadon, Teladorsagia circumcincta, munia. Arundelin ja Hamiltonin (1975) mukaan O. ostertagi -tartunnat naudoista lampaisiin ovat mahdollisia, mutta niitä tiedetään vuosikymmenien aikana tapahtuneen erittäin harvoin.

Piiskamadon munia (Trichuris sp.) löytyi kahdesta vasikasta ja yhdestä emosta elokuussa 2003 sekä kolmesta vasikasta heinä-elokuussa 2004. Karitsoista piiskamadon munia ei löytynyt. Ensimmäisen kesän elokuussa 20 \% karitsoista (maks. 540 epg) ja yksi yhteislaidunryhmän emo (20 epg) eritti Skrjabinema-kihomadon munia. On mahdollista, että emolehmällä ei ollut Skrjabinema-tartuntaa lainkaan. Todennäköisesti se oli niellyt ja sittemmin ulostanut karitsasta peräisin olleen munan. Vasikat olivat puhtaita. Kihomatoa ei toisena kesänä esiintynyt lainkaan.

Erot loismäärissä mono- ja yhteislaidunten välillä olivat pieniä. Kun naudat ja lampaat vuorottelivat samalla laitumella, vähenivät loiset lampaissa Marleyn ym. (2006) tutkimuksessa. Barger (1999) pitää nautojen ja lampaiden yhteislaidunnuksen vaikutusta loismääriin epäselvempänä. Yhteislaidunnuksen merkitys eri eläinlajien loismääriin riippuu ristiintartuntojen ohella laidunpaineesta ja sääoloista. Tässä tutkimuksessa laidunpaine yhteislaitumella oli noin $21 \%$ suurempi kuin monolaitumella. Mikäli eläintiheys on suuri, eläimet joutuvat syömään ruohoa lanta- ja papanakasojen vierestä ja saa- 
vat helpommin tartunnan. Märässä maassa loisten toukat nousevat ylemmäksi ruohojen korsille ja ovat täten paremmin eläinten saatavilla. Toinen kesä ei sääoloiltaan ollut yhtä edullinen kuin ensimmäinen. Tämä näkyi mm. tarjolla olevan ruohomäärän niukkuutena ja eläinten heikompina kasvuina. Suuria muutoksia loismäärissä ei kuitenkaan tapahtunut.

Pelkällä nautalaitumella vasikat kasvoivat paremmin kuin nauta-karitsalaitumella (Taulukko 2). Ensimmäisenä kesänä keskimääräinen painoero oli $15 \mathrm{~kg}(\mathrm{p}<0,001)$ ja toisena kesänä $9 \mathrm{~kg}(\mathrm{p}=0,09)$. Käytännön kannalta kasvuerot olivat merkityksettömiä. Emot olivat hyväkuntoisia sekä nauta- että nauta-karitsaryhmässä myös laidunkauden päättyessä. Karitsat kasvoivat tyydyttävästi, keskimäärin 160 g eläintä kohden päivässä. Teurastettaessa karitsat olivat sopivan rasvaisia eikä ruhojen myynti tuottanut vaikeuksia. Karitsoiden mukaanotto laitumelle lisäsi lihan kokonaistuotosta runsaat $150 \mathrm{~kg}$ ha ${ }^{-1}$ kesällä 2003 ja 94 kg ha ${ }^{-1}$ kesällä 2004. Lisäys saatiin aikaan karitsoiden kasvun kautta.

Taulukko 2. Eläinten elopainojen muutokset ja emojen kuntoluokka kesinä 2003-2004.

\begin{tabular}{|c|c|c|c|c|c|c|c|c|}
\hline & \multicolumn{2}{|c|}{ Naudat yksin } & \multicolumn{2}{|c|}{ Yhteislaidun } & \multicolumn{2}{|c|}{ SEM $^{1)}$} & \multicolumn{2}{|c|}{ Merkitsevyys $^{2)}$} \\
\hline & 2003 & 2004 & 2003 & 2004 & 2003 & 2004 & 2003 & 2004 \\
\hline Emojen painon muutos, kg & 53 & 27 & 28 & 4 & 7,1 & 5,7 & $*$ & $* *$ \\
\hline Emojen kunto ${ }^{3)}$ alussa & 3,5 & 3,2 & 3,3 & 3,2 & 0,15 & 0,15 & & \\
\hline Emojen kunto ${ }^{3)}$ lopussa & 3,5 & 3,3 & 3,4 & 3,0 & 0,15 & 0,16 & & $* *$ \\
\hline Vasikoiden painon muutos, kg & 105 & 92 & 90 & 83 & 2,4 & 4,0 & $* * *$ & 0 \\
\hline
\end{tabular}

Kaidunnukset olivat ajalla 4.6. - 26.8.2003 ja 8.6. - 31.8.2004. ${ }^{1)} \mathrm{SEM}=$ keskiarvon keskivirhe; ${ }^{2}$ Merkitsevyys $=* * *$ $(\mathrm{P}<0,001), * *(\mathrm{P}<0,01), *(\mathrm{P}<0,05), \mathrm{o}(\mathrm{P}<0,10) ;{ }^{3)}$ Asteikko 0-5 (0=laiha, 5=lihava).

\section{Johtopäätökset}

Emolehmien ja vasikoiden laiduntaminen yhdessä karitsoiden kanssa nosti laidunpainetta 21 \%:lla. Laidunpaineen nousu ei kuitenkaan lisännyt loisongelmaa. Loislääkityksen poisjättäminen vähensi kustannuksia. Yhteislaiduntaminen lisäsi lihan kokonaistuottoa hehtaarilla keskimäärin 120 kiloa. Tuoton lisäys tuli karitsoista.

\section{Kirjallisuus}

Arundel, J.H. \& Hamilton, D. 1975. The effect of mixed grazing of sheep and cattle on worm burdens in lambs. Australian Veterinary Journal 51, 336-440.

Barger, I.A. 1999. The role of epidemiological knowledge and grazing management for helminth control in small ruminants. International Journal of Parasitology 29, 41-47.

Gudmundsson, O., Thorgeirsson, S. \& Richter, S. H. 1983. Autumn grazing and paratism in fattening lambs under subartic conditions. $34^{\text {th }}$ Annual Meeting of the Study Commission EAAP, Madrid, 3.-6. October 1983. 8 p. Jackson, F. \& Coop, R.L. 2000. The development of anthelmintic resistance in sheep nematodes. Parasitology 120, S95-S107.

Jordan, H.E., Phillips, W.A., Morrison, R.D., Doyle, J.J. \& McKenzie, K. 1988. A 3-year study continuous mixed grazing of cattle and sheep: parasitism of offspring. International Journal of Parasitology 8, 779-784.

Lowman, B.G., Scott, N.A. \& Sommerville, S.H. 1976. Condition Scoring of Cattle. The East of Scotland College of Agriculture. Animal Production, Advisory and Development Department. Bulletin No. 6. 31 p.

Marley, C.L., Fraser, M.D., Davies, D.A., Rees, M.E., Vale, J.E. \& Forbes, A.B. 2006. The effect of mixed or sequential grazing of cattle and sheep on the faecal egg counts and growth rates of weaned lambs when treated with anthelmintics. Veterinary Parasitology 142, 134-141.

Morris, T.R. 1999. Experimental Design and Analysis in Animal Sciences. CABI Publishing, Wellingford, UK. 208 p.

Sormunen-Cristian, R., Manninen, M. \& Jauhiainen, L. 2006. Laidun tehokäyttöön emolehmien ja karitsoiden yhteislaidunnuksella. Julkaisussa: Maataloustieteen Päivät 2006 [verkkojulkaisu]. Suomen Maataloustieteellisen Seuran julkaisuja no 21. Toim. Anneli Hopponen. Viitattu [26.11.2007]. Julkaistu 9.1.2006. Saatavilla Internetissä: http:///www.smts.fi (Laidun tehokäyttöön emolehmien ja karitsoiden yhteislaidunnuksella). ISBN 951-9041-49-4 